\title{
Transcortical Removal of Third Ventricular Colloid Cysts: Comparison of Conventional, Guided Microsurgical and Endoscopic Approaches and Review of the Literature
}

\author{
Pulat Akin SABANCl ${ }^{1}$, Yavuz ARAS ${ }^{1}$, Achmet ALI ${ }^{2}$, Tugrul Cem UNAL' ${ }^{1}$, Duygu DOLEN ${ }^{1}$, Serra SENCER ${ }^{3}$, Nail IZGI ${ }^{1}$, \\ Faruk UNAL ${ }^{1}$, Orhan BARLAS ${ }^{1}$
}

${ }^{1}$ Istanbul University, Istanbul School of Medicine, Department of Neurosurgery, Istanbul, Turkey

${ }^{2}$ Istanbul University, Istanbul School of Medicine, Department of Anesthesiology, Istanbul, Turkey

${ }^{3}$ Istanbul University, Istanbul School of Medicine, Department of Radiology, Istanbul, Turkey

\section{ABSTRACT}

AIM: To compare the clinical results of different transcortical approaches for the removal of third ventricular colloid cysts (CC).

MATERIAL and METHODS: Records of 41 colloid cyst patients who underwent transcortical conventional microsurgical, microsurgical with the aid of stereotactically guided cylindrical retractor (minitubular), and endoscopic removal between 1999 and 2015 were retrospectively analyzed. The clinical results of these three different transcortical surgical approaches were compared and a literature review of published series was conducted.

RESULTS: Ages ranged between 16 and 66 years (mean: 36.8). There were 18 female and 23 male patients. Headache was the main presenting symptom. The mean CC diameter was $15.5 \mathrm{~mm}$. Intraventricular hemorrhage was encountered in 2 patients. Three patients needed postoperative ventriculoperitoneal shunt surgery. Postoperative seizures were seen in 3 , postoperative neurological deficit in 3 and residual tumor in 2 patients. The conventional approach resulted in significantly higher rates of postoperative seizure compared to the minitubular and endoscopic approaches $(\mathrm{p}=0.012)$. The rate of residual cyst was significantly higher in endoscopic approach compared to conventional and minitubular approaches $(p=0.024)$. Conventional approach led to significantly higher rates of neurological deficit compared to the two other approaches $(p<0.05)$.

CONCLUSION: With respect to complication rates, the stereotactic and endoscopic approaches are both safe and reliable compared to conventional microsurgical approach that has unacceptably high rates of seizures and neurological deficit. Concerning completeness of removal, both microsurgical approaches are by far superior to neuroendoscopy. The stereotactic microsurgical approach compares favorably in both respects with endoscopic and conventional microsurgical approaches.

KEYWORDS: Colloid Cyst, Third Ventricle, Surgical Treatment, Microsurgery, Neuroendoscopy, Stereotaxy, Tubular System

\section{INTRODUCTION}

$\mathrm{T}$ Third ventricular colloid cysts (CC) are rare tumors that constitute $0.5-2 \%$ of intracranial $(20,23)$ and $15-20 \%$ of intraventricular tumors (31). These non-neoplastic lesions are believed to arise from misplacement of endodermal tissue in the anterosuperior portion of the third ventricle during development of the central nervous system (35). Although colloid cysts are benign tumors, they may continue to enlarge to occlude the foramen of Monro and are known to lead to sudden death $(9,21,39)$.

Standard surgical approaches for the removal of CC traverse either the corpus callosum or the frontal cortex. 
The conventional transcortical approach has been reported to result in high seizure rates due to parenchymal injury $(8,12,13)$. The transcallosal approach may not lead to seizures, but the risks of both venous infarction and interhemispheric disconnection syndrome are significant $(19,33,43)$. To counter these problems, less invasive transcortical approaches were developed to reduce neuronal damage in the frontal lobe. Cortical incision and parenchymal dissection were minimized by the use of stereotactically guided cylindrical retractor $(4,6,25)$. Cortical injury was further reduced by the introduction of the neuroendoscope $(14,18,21,22,28,30,46)$.

We present a retrospective review of our transcortically operated cases of colloid cyst and a review of the literature to see whether this progressive reduction in the size of the cortical incision and related parenchymal injury over the last 15 years was reflected in the clinical results of $\mathrm{CC}$ removal.

\section{MATERIAL and METHODS}

The data of 41 patients, who were operated for CC between the years 1999 and 2015 at the Department of Neurosurgery Istanbul University, were retrospectively reviewed. Eleven patients underwent resection of $\mathrm{CC}$ by conventional microsurgical transventricular transforaminal approach (conventional approach), 21 patients with the microsurgical transventricular transforaminal approach via a stereotactically guided cylindrical retractor (minitubular approach), and nine patients with the endoscopic transfrontal approach (endoscopic approach). Age, sex, signs and symptoms on admission, duration of symptoms, computerized tomography (CT) and magnetic resonance imaging (MRI) details, maximal CC diameter measured in millimeters on MRI, need for ventriculostomy (preoperative or postoperative), the surgical approach, surgical complications, shunt dependency, follow-up period (in months), presence of residual cyst, and any recurrence were noted. Surgery was offered when a CC had a diameter greater than $10 \mathrm{~mm}$ or caused hydrocephalus, whether or not it was symptomatic. This study includes only those patients that underwent surgery. Current modified Rankin Score of patients were determined by clinical examination or telephone interviews (36). Histopathological diagnosis of CC was available for all patients. Clinical results of the three surgical approaches were compared with each other, and with the results of our literature review.

\section{Operative Technique}

Surgical approach was selected according to surgeons' preference. Both conventional and minitubular approaches were performed via a frontal craniotomy placed just anterior to the coronal suture. Conventional approaches were performed freehand, without the use of neuronavigation. Minitubular approach, introduced independently by the senior author, is described in detail elsewhere (4). Briefly, a cylindrical retractor $14 \mathrm{~mm}$ in diameter is placed in the instrument holder of the Leksell囚 stereotactic frame (Elekta AB, Stockholm, Sweden) and directed to the target, for which a point in the frontal horn just lateral to the foramen of Monro was chosen, and the cyst removed microsurgically through the retractor. The endoscopic approach was conducted via a standard neuroendoscope working with a single instrument technique having a $0^{\circ}$ view angle with a $2.7 \mathrm{~mm}$ channel diameter and $185 \mathrm{~mm}$ working length (Richard Wolf $\mathrm{GmbH} \otimes$, Knittlingen, Germany). All endoscopic cases were performed in pure endoscopic fashion. In none of the cases was an endoscope-assisted approach used. The endoscopic approaches were performed through a single burrhole (Figure $1 \mathrm{~A}-\mathrm{C}$ ). The maximal diameter of craniotomy was $6 \mathrm{~cm}$ for conventional and $4 \mathrm{~cm}$ for minitubular approaches. The length of cortical incisions were 20-30 $\mathrm{mm}$ in conventional, $10-14 \mathrm{~mm}$ in minitubular and 4-6 $\mathrm{mm}$ in endoscopic approaches (Figure 2A-C).

\section{Statistical Analysis}

Distribution of quantitative data was evaluated using the Kurtosis and Skewness tests. Data are presented as mean \pm standard deviation for normally distributed quantitative and as median and minimum-maximum where the quantitative data were not normally distributed. Qualitative data are presented as number of cases. Statistical analyses performed were: Student-T test, ANOVA test, Tukey subgroup test for comparison of normally distributed quantitative variants and Mann-Whitney $U$ test, Kruskal-Wallis test for comparison of not normally distributed quantitative variants. Chi-square test was used to compare qualitative variants. Cramer's V correlation test was used to assess correlations between meningitis and shunt dependency (Qualitative data). $p<0.05$ was considered as statistically significant. Statistical analyses were carried out using SPSS for Windows version 15.0 (SPSS Inc. Chicago, IL, USA).

\section{Literature Review}

Surgical series of colloid cysts with more than ten patients published between 1989 and 2015 were reviewed and series containing patients operated with conventional transfrontal microsurgical, microsurgical with stereotactically guided cylindrical retractor and transfrontal endoscopic approaches were included in this study. Patients operated via the transcallosal approach or series containing only nonhydrocephalic patients (45) were excluded. The data extracted from the reports included the surgical technique, total number of patients, age, sex, presence of hydrocephalus, cyst diameter, conversion to craniotomy, residual tumor, shunt dependency, intraventricular hemorrhage, infection, postoperative seizure, permanent neurological deficit, mortality and follow-up period. Seizure, permanent neurological deficit and completeness of resection rates were compared in the three surgical approach groups.

\section{- RESULTS}

\section{Clinical Features}

Ages ranged between 16 and 66 years (mean: 36.8). There were 18 female and 23 male patients. Headache was the most common presenting symptom. Other presenting symptoms of the patients are listed in Table I. Six patients that were comatose on admission underwent pre-operative external ventricular drainage, which was unable to reverse the fatal 
clinical course in only one (Patient 11) of these six patients. One patient (Patient 23) had been operated for shunt surgery elsewhere before being referred to our clinic for CC resection

Table I: Presenting Symptoms of the Patients

\begin{tabular}{lcc}
\hline Symptoms & Number of Patients & (\%) \\
\hline Headache & 30 & 73 \\
\hline Confusion & 7 & 17 \\
\hline Nausea/Vomiting & 6 & 15 \\
\hline Coma & 6 & 15 \\
\hline Dizziness & 4 & 10 \\
\hline Gait disturbance & 3 & 7 \\
\hline Visual disturbance & 2 & 5 \\
\hline Incontinence & 2 & 5 \\
\hline Amnesia & 2 & 5 \\
\hline Parkinsonism & 1 & 2 \\
\hline
\end{tabular}
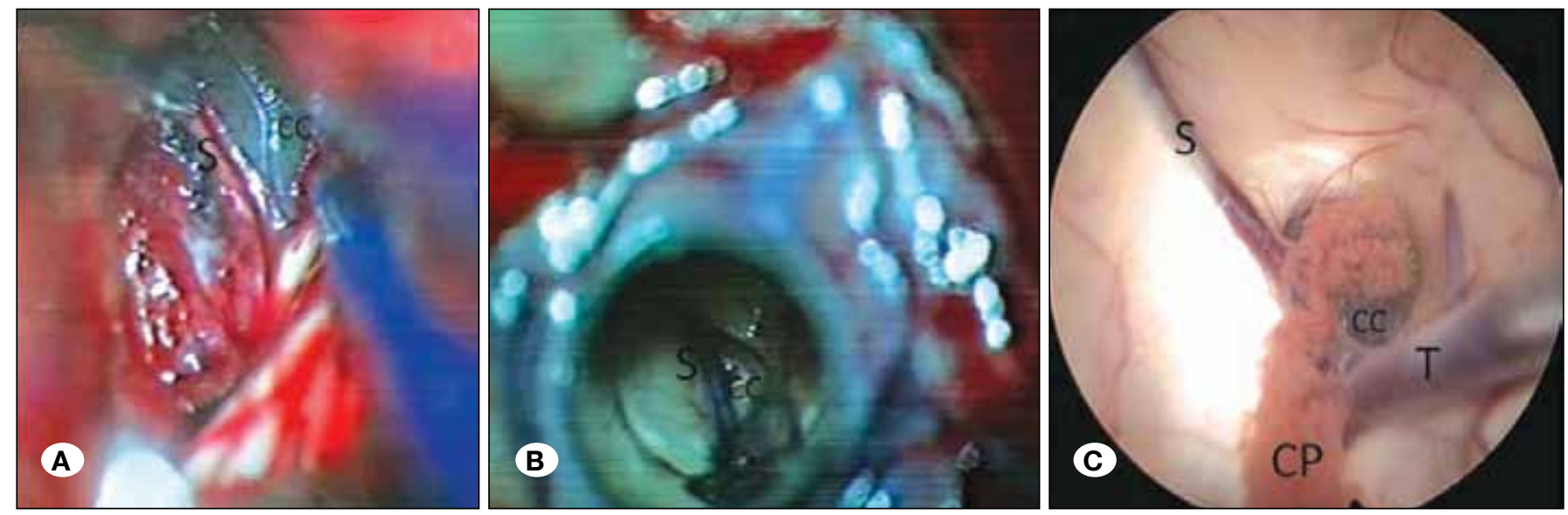

Figure 1: Intraoperative views of three different approaches; A) Conventional, B) Minitubular, C) Endoscopic (CC: Colloid cyst, CP: Choroid plexus, S: Septal vein, T: Thalamostriate vein).
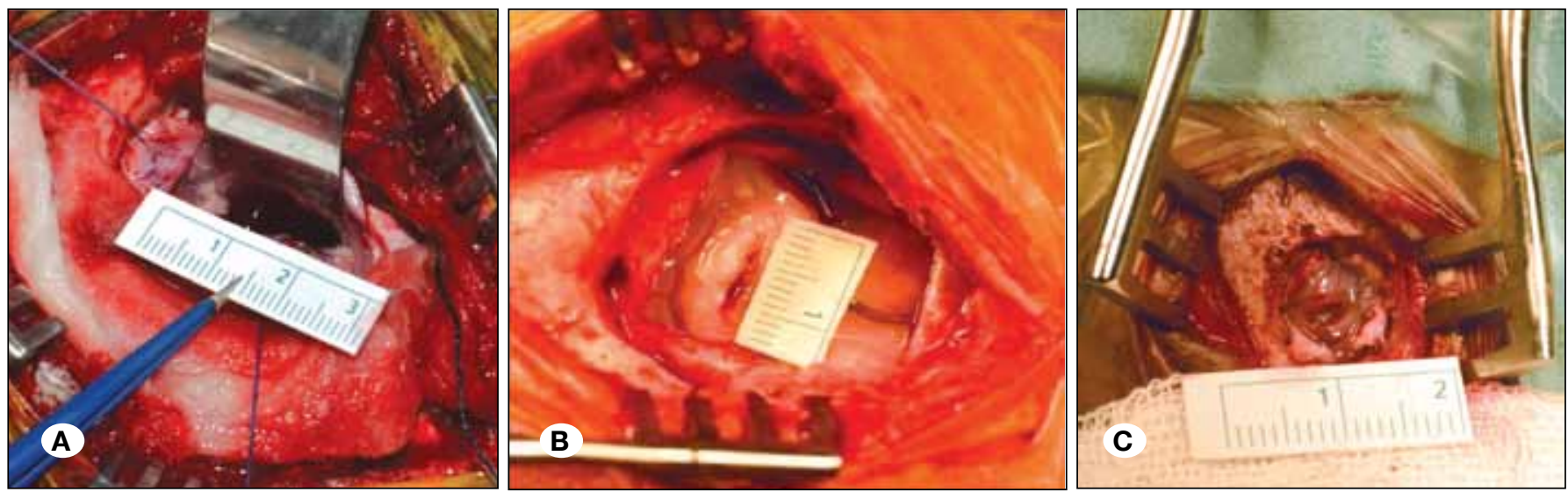

Figure 2: Photographs of cortical incisions in different lengths specific to the approaches; A) Conventional approach, B) Minitubular approach, C) Endoscopic approach. 
Table II: Clinical and Radiological Details of the Patients

\begin{tabular}{|c|c|c|c|c|c|c|c|c|c|c|c|c|}
\hline $\begin{array}{l}\text { Pat } \\
\text { No }\end{array}$ & $\begin{array}{l}\text { Age } \\
(y) / \\
\text { Sex }\end{array}$ & Symptom & Duration & $\begin{array}{l}\text { Previous } \\
\text { Procedure }\end{array}$ & $\begin{array}{c}\text { Preop } \\
\text { MR-T1w } \\
\text { (Intensity) }\end{array}$ & $\begin{array}{c}\text { Preop } \\
\text { CT * } \\
\text { (Density) }\end{array}$ & $\begin{array}{l}\text { Cyst } \\
\text { Dia }\end{array}$ & $\begin{array}{l}\text { Vent. } \\
\text { drain. }\end{array}$ & $\begin{array}{l}\text { Surgical } \\
\text { approach }\end{array}$ & Complication & $\begin{array}{l}\text { Rankin } \\
\text { Score }\end{array}$ & $\begin{array}{l}\text { FU* } \\
\text { (mo) }\end{array}$ \\
\hline 2 & 48,M & $\mathrm{HA}$ & $2 w$ & - & Hyper & Hyper & 15 & - & Con & - & 0 & 160 \\
\hline 3 & $18, M$ & $\mathrm{HA}$ & $1 y$ & - & Iso & - & 12 & - & Con & $\begin{array}{l}\text { Contusion, } \\
\text { infarct, } \\
\text { hemiparesis, } \\
\text { seizure }\end{array}$ & 4 & 143 \\
\hline 4 & $39, \mathrm{M}$ & $\mathrm{HA}, \mathrm{C}$ & $3 d$ & - & Hyper & Hyper & 15 & $\begin{array}{l}\text { Postop } \\
(x 2)\end{array}$ & Con & $\begin{array}{l}\text { IVH, Meningitis, } \\
\text { hemiparesis } \\
\text { HS-shunt op } \\
\text { Reop- shunt }\end{array}$ & 5 & 124 \\
\hline 6 & $58, M$ & $\begin{array}{l}\mathrm{HA} \\
\mathrm{D}\end{array}$ & $9 \mathrm{~m}$ & - & Hyper & Hyper & 20 & - & Con & $\begin{array}{l}\text { Meningitis, } \\
\text { seizure }\end{array}$ & 0 & 87 \\
\hline 7 & $37, \mathrm{~F}$ & $\mathrm{D}$ & $1 y$ & - & Hypo & Hyper & 14 & - & Con & - & 0 & 70 \\
\hline 8 & $28, M$ & $\mathrm{HA}$ & $5 \mathrm{~m}$ & - & Iso & Hyper & 18 & - & Con & Seizure & 1 & 65 \\
\hline 9 & $41, \mathrm{~F}$ & GD & $1 \mathrm{y}$ & - & Hyper & Hyper & 12 & - & E\& Con & $\begin{array}{c}\text { During } \\
\text { Endoscopy } \\
\text { hemorragy from } \\
\text { cho plexus- IVH, } \\
\text { shifted to Con }\end{array}$ & 0 & 54 \\
\hline
\end{tabular}

\begin{tabular}{|c|c|c|c|c|c|c|c|c|c|c|c|c|}
\hline & $40, F$ & $\begin{array}{l}\text { HA } \\
\text { N/N } \\
\text { LoC }\end{array}$ & $2 d$ & - & -(emergency) & $\begin{array}{c}\text { Iso (14 } \\
\text { mm hyper } \\
\text { inside) }\end{array}$ & 23 & Preop & Con & Ex & 6 & \\
\hline 12 & $22, \mathrm{~F}$ & LoC & $1 d$ & - & Iso & Hyper & 18 & Preop & MT & - & 0 & 202 \\
\hline 13 & $41, \mathrm{M}$ & LoC & $1 w$ & - & Hyper & Hyper & 22 & Preop & MT & - & 0 & 195 \\
\hline 14 & $26, \mathrm{M}$ & LoC & $1 y$ & - & Hyper & Hyper & 18 & Preop & MT & Meningitis & 0 & 190 \\
\hline 15 & $62, \mathrm{M}$ & P,GD & $4 \mathrm{~m}$ & $\mathrm{E}$ & Iso & Hyper & 21 & - & MT & - & 0 & 186 \\
\hline 16 & $17, \mathrm{M}$ & HA,VD & $1 \mathrm{~m}$ & - & Hyper & Iso & 19 & - & MT & $\begin{array}{c}\text { Closed CSF } \\
\text { Fistula }\end{array}$ & 0 & 173 \\
\hline 17 & $40, \mathrm{M}$ & $\mathrm{HA}$ & $3 y$ & - & Hypo & Iso & 16 & - & MT & - & 0 & 172 \\
\hline 18 & $51, \mathrm{M}$ & $\mathrm{HA}, \mathrm{C}$ & $2 \mathrm{~m}$ & - & Iso & Iso & 8 & - & MT & - & 0 & 171 \\
\hline 19 & $36, F$ & HA, GD & $3 m$ & - & Hyper & Iso & 18 & - & MT & - & 0 & 170 \\
\hline 20 & $22, \mathrm{M}$ & LoC & $3 d$ & - & Hyper & Iso & 17 & Preop & MT & - & 0 & 166 \\
\hline
\end{tabular}


Table II: Cont.

\begin{tabular}{|c|c|c|c|c|c|c|c|c|c|c|c|c|}
\hline 21 & $17, \mathrm{M}$ & $\begin{array}{c}\text { HA, } \\
\text { diplopia }\end{array}$ & $3 w$ & - & Нypo & Iso & 19 & - & MT & - & 0 & 165 \\
\hline 22 & $17, \mathrm{~F}$ & $\mathrm{HA}$ & $3 w$ & - & Hypo & Нyро & 19 & - & MT & - & 0 & 155 \\
\hline 23 & $38, M$ & $\mathrm{HA}$ & $4 m$ & $\begin{array}{l}\text { Shunt op } \\
(3 \mathrm{~m} \text { ago) }\end{array}$ & Hyper & Hyper & 13 & - & MT & - & 0 & 140 \\
\hline 24 & $33, \mathrm{M}$ & $\mathrm{HA}, \mathrm{C}$ & $6 m$ & - & Hyper & Hyper & 15 & - & MT & - & 0 & 139 \\
\hline 25 & $47, \mathrm{M}$ & $\mathrm{HA}$ & $3 w$ & - & Hyper & Hyper & 18 & - & $\mathrm{MT}$ & - & 0 & 86 \\
\hline 26 & $30, F$ & $\mathrm{HA}$ & $3 \mathrm{~m}$ & - & Iso & Hyper & 7 & - & MT & - & 0 & 75 \\
\hline 27 & $60, \mathrm{M}$ & $\mathrm{D}$ & $4 \mathrm{~m}$ & - & Hyper & Hyper & 9 & - & MT & - & 0 & 68 \\
\hline 28 & $29, F$ & $\mathrm{HA}, \mathrm{C}$ & $3 m$ & - & Hyper & Hyper & 15 & - & MT & - & 0 & 55 \\
\hline 29 & $31, F$ & N/N, C & $2 d$ & - & Iso & Hyper & 15 & - & $\mathrm{MT}$ & Meningitis & 0 & 12 \\
\hline 30 & $66, F$ & $A, I$ & $4 d$ & - & Нypo & Iso & 16 & - & MT & $\begin{array}{c}\text { EDH under } \\
\text { craniotomy } \\
\text { (conservative) }\end{array}$ & 0 & 7 \\
\hline 31 & $42, \mathrm{M}$ & $\mathrm{HA}, \mathrm{N}$ & $10 d$ & - & Iso & Hyper & 22 & - & $\mathrm{MT}$ & - & 0 & 6 \\
\hline 32 & $20, M$ & $\mathrm{HA}, \mathrm{N}$ & $2 y$ & - & Iso & Hyper & 11 & - & MT & - & 0 & 2 \\
\hline 33 & $26, F$ & $\mathrm{HA}, \mathrm{N}$ & $2 w$ & - & Iso & Iso & 16 & - & $E$ & & 0 & 81 \\
\hline 34 & $48, F$ & $\mathrm{HA}, \mathrm{N} / \mathrm{V}$ & $1 \mathrm{w}$ & - & Hyper & Hyper & 18 & - & $E$ & - & 1 & 68 \\
\hline 35 & $45, F$ & HA ,LoC & $1 \mathrm{~d}$ & - & Hypo & Hyper & 15 & Preop & $E$ & Meningitis & 0 & 45 \\
\hline 36 & $32, F$ & $\mathrm{HA}$ & $10 \mathrm{~m}$ & - & Hyper & Hyper & 9 & - & $E$ & - & 0 & 31 \\
\hline 37 & $34, \mathrm{M}$ & Incidental & - & $\begin{array}{l}\text { Diagnosed } \\
1 \text { m before } \\
\text { (pit. op.) }\end{array}$ & Hyper & Hyper & 13 & - & $E$ & Residue & 0 & 24 \\
\hline 38 & $32, \mathrm{~F}$ & $\mathrm{HA}$ & $2 y$ & - & Hyper & Hyper & 16 & - & $E$ & $\begin{array}{c}\text { Residue, Shunt } \\
\text { op }\end{array}$ & 0 & 20 \\
\hline 39 & $38, M$ & $\mathrm{HA}, \mathrm{C}$ & $6 \mathrm{~m}$ & - & Hyper & Hyper & 14 & - & $E$ & - & 0 & 17 \\
\hline 40 & $52, \mathrm{M}$ & HA, D & $3 m$ & - & Iso & Iso & 13 & - & $E$ & - & 0 & 15 \\
\hline 41 & $45, \mathrm{~F}$ & $\mathrm{HA}$ & $1 \mathrm{~m}$ & - & Hyper & Hyper & 18 & - & $E$ & - & 0 & 8 \\
\hline
\end{tabular}

Cyst dia: Cyst diameter in mm, Preop: Preoperative, FU(mo): Follow-up (months), HA: Headache, N: Nausea, V: Vomitting, A: Amnesia, LoC: Loss of Consciousness (GCS <8), I: Incontinance, GD: Gait disturbance, D: Dizziness, C: Confusion, P: Parkinsonism, VD: Visual Disturbance, y: years, m: months, w: weeks, d: days, Con: Conventional approach, MT: Minitubular Approach, Stereotaxy guided Transventricular Microsurgery with a tubular sysytem, E: Endoscopic, IVH: Intraventricular hemorrhage, pit: pituitary, Ex: Exitus, - : none, M: Male, F: Female, Vent drain: Ventricular drainage, Pat No: Patient number.

to a conventional approach when the bleeding occurred intraoperatively (Figure 4A-E).

Surgery was complicated by bacterial meningitis in six patients. Patients 4, 10 and 14 and were infected with coagulasenegative Staphylococcus, patient six with methicillin-resistant Staphylococcus aureus, patient 29 with Klebsiella, and patient 35 with Acinetobacter strains. There were no significant differences among surgical approaches in terms of postoperative meningitis $(p=0.380)$.

In the postoperative period, three patients required insertion of ventriculoperitoneal shunts. Of those, patient 38 who was operated via endoscopy had undergone subtotal excision. The other two patients that developed meningitis were both operated via the conventional approach and both had undergone an external ventricular drainage insertion preoperatively. Postoperative shunt dependence was found to be statistically insignificant among surgical groups $(p=0.152)$ whereas a correlation was found between meningitis and shunt dependence $(\mathrm{p}=0.008, \mathrm{~V}=0.414)$.

All patients that were operated for $\mathrm{CC}$ had been prescribed antiepileptic drugs (Phenytoin 2x150 mg/day or levatiracetam $2 \times 500 \mathrm{mg} /$ day, orally) for a period of 6 months in the postop- 
erative period if seizure free. Three patients (7.3\%) (Patient 3, 6 and 8), all of whom were operated via the conventional approach, had postoperative seizures in this series. Two of these were on phenytoin, the third on levatiracetam. After recognition of the seizure, their antiepileptic drug dosages had been increased and no further seizures that needed additional electroencephalography (EEG) investigation occurred. The conventional approach resulted in significantly higher rates of postoperative seizure compared to the minitubular and endoscopic approaches $(p=0.012)$.

Two patients had postoperative residual cysts. These were patient 37 and 38, both of whom had been operated via the endoscope, and were discharged with no symptoms at all. No other residual cysts were determined in the entire cohort. The rate of residual cyst was significantly higher in the endoscopic

Table III: The Total Number of Patients for Whom the Information was Available is Shown in Parantheses and in the Denominator When Applicable

\begin{tabular}{|c|c|c|c|c|c|c|c|}
\hline $\begin{array}{l}\text { Type of Surgery } \\
\text { Series }\end{array}$ & \multicolumn{2}{|c|}{ Conventional Approach } & \multicolumn{2}{|c|}{ Minitubular Approach } & \multicolumn{2}{|c|}{ Endoscopic Approach } & Total \\
\hline Mean age (years) & $\begin{array}{c}35.6 \\
(61 p)\end{array}$ & 39 & 41.8 & 35.6 & 42.1 & 39.1 & \\
\hline $\operatorname{Sex}(M / F)$ & $48 / 43$ & $7 / 4$ & $\begin{array}{l}27 / 19 \\
(46 p)\end{array}$ & $13 / 8$ & $261 / 199$ & $3 / 6$ & $\begin{array}{c}359 / 279 \\
(638 p)\end{array}$ \\
\hline Hydrocephalus & $\begin{array}{c}75 \% \\
(46 / 61)\end{array}$ & $\begin{array}{c}100 \% \\
(11 / 11)\end{array}$ & $\begin{array}{c}84 \% \\
(43 / 51)\end{array}$ & $\begin{array}{c}100 \% \\
(21 / 21)\end{array}$ & $\begin{array}{c}80 \% \\
\left(369 / 460^{\star}\right)\end{array}$ & $\begin{array}{l}89 \% \\
(8 / 9)\end{array}$ & $\begin{array}{c}81 \% \\
(497 / 613)\end{array}$ \\
\hline Length of incision (mm) & & $20-30$ & & $10-14$ & & $4-6$ & \\
\hline Conversion to craniotomy & NA & NA & NA & NA & $\begin{array}{c}3 \% \\
(8 / 235)\end{array}$ & $\begin{array}{l}11 \% \\
(1 / 9)\end{array}$ & $\begin{array}{c}4 \% \\
(9 / 244)\end{array}$ \\
\hline Residual tumor & $\begin{array}{c}2 \% \\
(1 / 61)\end{array}$ & $\begin{array}{c}0 \% \\
(0 / 11)\end{array}$ & $\begin{array}{c}3 \% \\
(1 / 39)\end{array}$ & $\begin{array}{c}0 \% \\
(0 / 21)\end{array}$ & $\begin{array}{c}28 \% \\
(115 / 407)\end{array}$ & $\begin{array}{l}22 \% \\
(2 / 9)\end{array}$ & $\begin{array}{c}22 \% \\
(120 / 548)\end{array}$ \\
\hline Shunt dependency & $\begin{array}{c}5 \% \\
(4 / 91) \\
\end{array}$ & $\begin{array}{l}18 \% \\
(2 / 11) \\
\end{array}$ & $\begin{array}{c}10 \% \\
(5 / 51)\end{array}$ & $\begin{array}{c}0 \% \\
(0 / 21) \\
\end{array}$ & $\begin{array}{c}9 \% \\
(39 / 442)\end{array}$ & $\begin{array}{l}11 \% \\
(1 / 9)\end{array}$ & $\begin{array}{c}8 \% \\
(50 / 625) \\
\end{array}$ \\
\hline IVH & $\begin{array}{c}0 \% \\
(0 / 61) \\
\end{array}$ & $\begin{array}{c}9 \% \\
(1 / 11)\end{array}$ & $\begin{array}{c}0 \% \\
(0 / 51) \\
\end{array}$ & $\begin{array}{c}0 \% \\
(0 / 21)\end{array}$ & $\begin{array}{c}3 \% \\
(12 / 460)\end{array}$ & $\begin{array}{l}11 \% \\
(1 / 9)\end{array}$ & $\begin{array}{c}2 \% \\
(14 / 613)\end{array}$ \\
\hline Mortality & $\begin{array}{c}3 \% \\
(2 / 71)\end{array}$ & $\begin{array}{c}9 \% \\
(1 / 11)\end{array}$ & $\begin{array}{c}0 \% \\
(0 / 51)\end{array}$ & $\begin{array}{c}0 \% \\
(0 / 21)\end{array}$ & $\begin{array}{c}1 \% \\
(3 / 460)\end{array}$ & $\begin{array}{c}0 \% \\
(0 / 9)\end{array}$ & $\begin{array}{c}1 \% \\
(6 / 623)\end{array}$ \\
\hline Mean FU period (mo) & $\begin{array}{c}45.1 \\
(86 p) \\
\end{array}$ & 102.8 & 28.8 & 120.7 & 40.6 & 34.3 & \\
\hline Range of FU & & $0-170$ & $3-121$ & $2-202$ & $0-147$ & $8-81$ & $0-202$ \\
\hline
\end{tabular}

NA: Not applicable, p: patients, mm: milimeters, FU: Follow-up, mo: months, M: male, F: female, IVH: Intraventricular hemorrhage *Two patients had pre-operative shunt insertion. 
approach compared to the conventional and minitubular approaches $(p=0.024)$.

Permanent neurological deficits were encountered in three (7.3\%) patients: patient 3, 4 and 10 . These three patients, all of whom were operated via a conventional approach, remained hemiparetic. Hemiparesis was caused by venous infarction in two and intraventricular hemorrhage in the third patient. In the present series, postoperative disconnection syndrome or memory deficit did not occur in any of the patients. The conventional approach led to significantly higher rates of neurological deficit compared to the two other approaches $(p<0.05)$.

\section{Mortality}

Only one patient (Patient 11) succumbed in this series. She was comatose with dilated pupils on admission. Brain CT showed dilated ventricles and diffuse cerebral edema due to a colloid cyst and signs of uncal herniation (Figure 5). Despite an urgent operation following external ventricular drainage, she died.
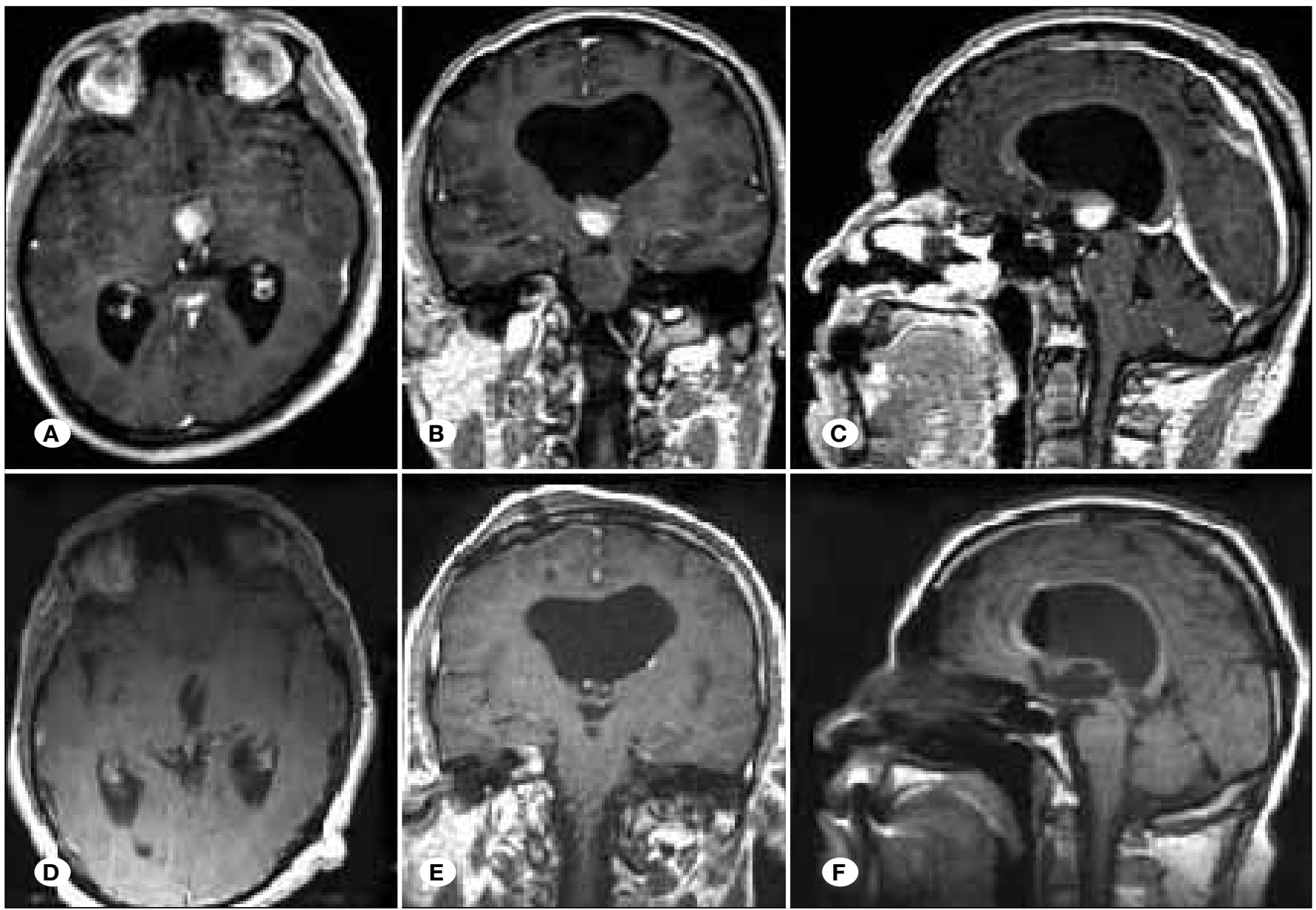

Figure 3: Preoperative $(\mathbf{A}, \mathbf{B}, \mathbf{C})$ and postoperative (D,E,F) axial, coronal and sagittal T1 W postcontrast MR images of patient 39, show total removal of the colloid cyst located centrally in the foramen of Monro.

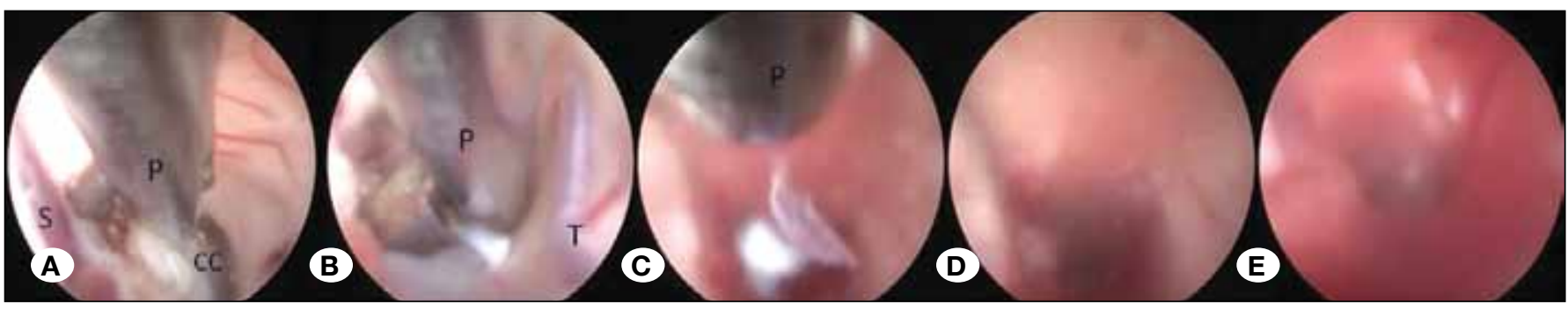

Figure 4A-E: Intraoperative view of intraventricular hemorrhage. A massive bleeding occured after a part of CC was removed via punch forceps (CC: Colloid cyst, P: Punch forceps, S: Septal vein, T: Thalamostriate vein). 

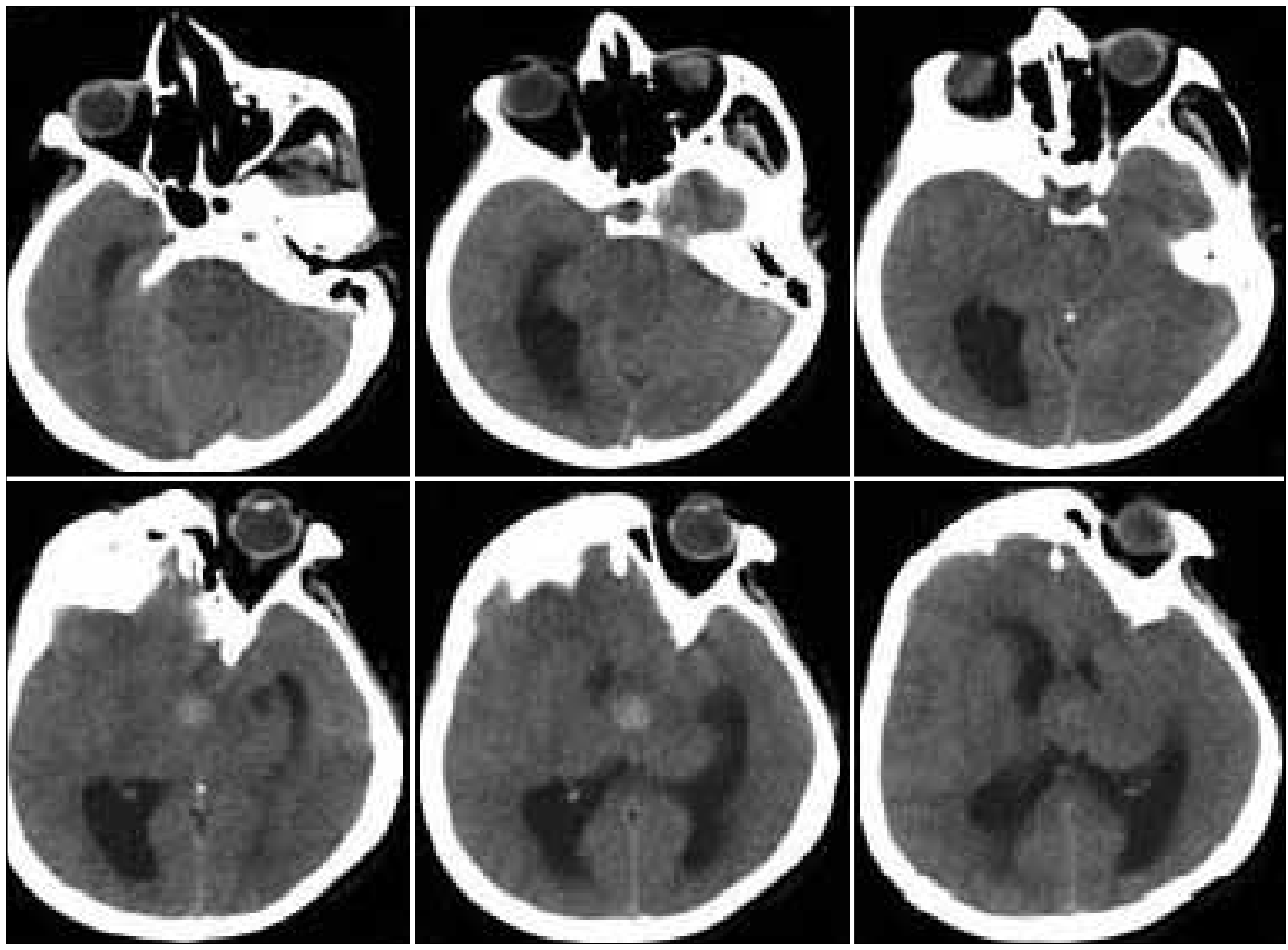

Figure 5: Admission CT of patient 11. A CC with $23 \mathrm{~mm}$ diameter (isodense) and $14 \mathrm{~mm}$ hyperdense center. The perimesencephalic cisterns could not be identified clearly.

\section{Follow-up}

Mean follow-up period was 102.8 months for conventional, 120.7 months for minitubular and 34.3 months for endoscopic approaches (Table III). Six of 11 patients operated via the conventional approach, 21 of 21 patients operated via the minitubular approach, and 8 of 9 patients in the endoscopy group had modified Rankin Scale scores of 0.

\section{Literature Review}

The results of our literature review are presented in Table IV. The results of the comparison of the present series with our literature review of 602 patients are summarized in Table III. The mean ages were $35.6,41.8,42.1$ years in the conventional, minitubular and endoscopic approaches, respectively. Hydrocephalus was present in $75 \%$ of conventional, $84 \%$ of minitubular and $80 \%$ of endoscopic cases. Residual tumor was detected in $2 \%, 3 \%, 28 \%$ of conventional, minitubular and endoscopic patients, respectively. The rates of postoperative seizure were $13 \%$ in conventional, $4 \%$ in minitubular and $0.5 \%$ in endoscopic cases. A neurological deficit was found in $3 \%$ of patients in conventional, $2 \%$ in minitubular and $6 \%$ in endoscopic cases (Table III) $(1,3-6,8,11,13,14,16$ $18,22,24,26,28,30,41,42,46,48)$

For minitubular and endoscopic approaches, the clinical results of the present series are parallel to the literature review. However, the conventional approach in the present series had significantly higher rates of intraventricular hemorrhage $(p=0.018)$, infection $(p=0.035)$ and neurological deficit $(p=0.04)$ than the literature review (Table III).

When the three approaches in our literature review were compared, the seizure rate was significantly higher in the conventional approach than the minitubular and endoscopic approaches $(p<0.001)$. In terms of residue, the endoscopic approach had significantly higher rates of residual cyst compared to conventional and minitubular approaches $(p<0.001)$. No statistically significant difference was found between the three approaches regarding permanent neurological deficit $(p=0.738)$. 


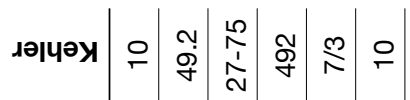

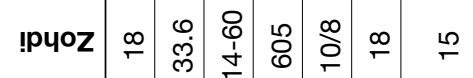

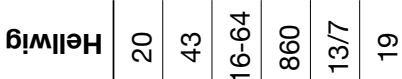

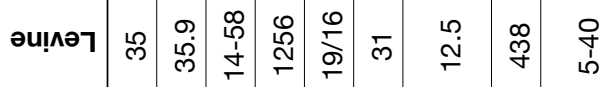

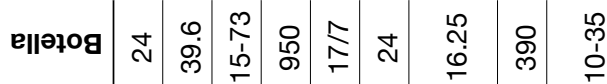

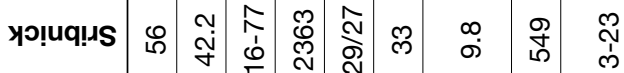

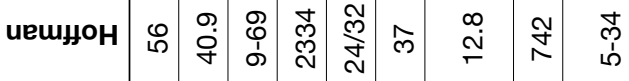

uos!!M $\approx$ ก

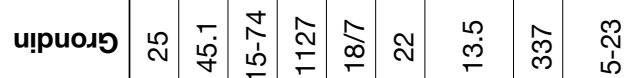

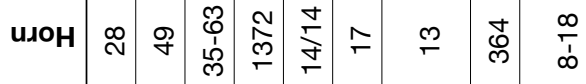

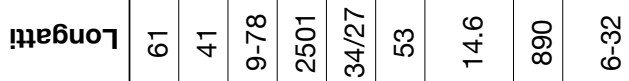

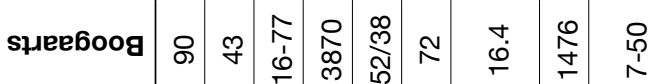

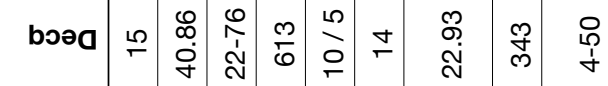

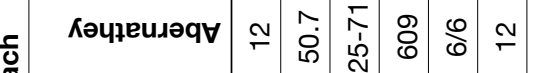

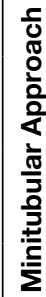

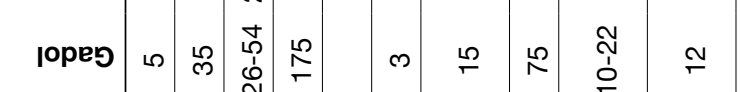

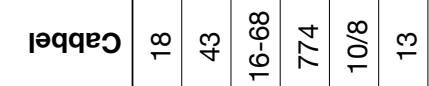

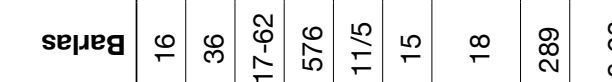

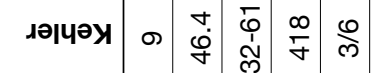

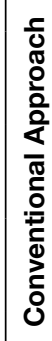

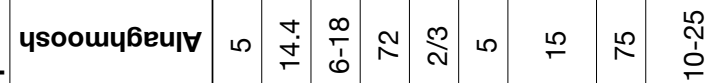

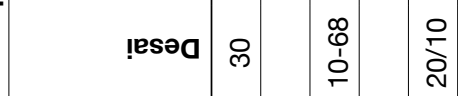

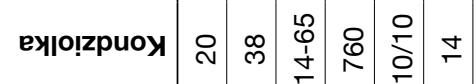

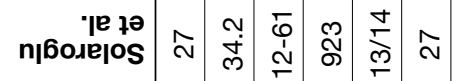

$\stackrel{0}{\underline{\underline{0}}}$

需

$\geq$

$\frac{\frac{0}{0}}{\frac{10}{10}}$
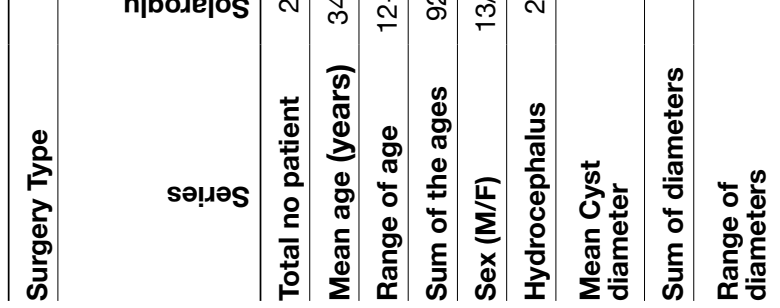

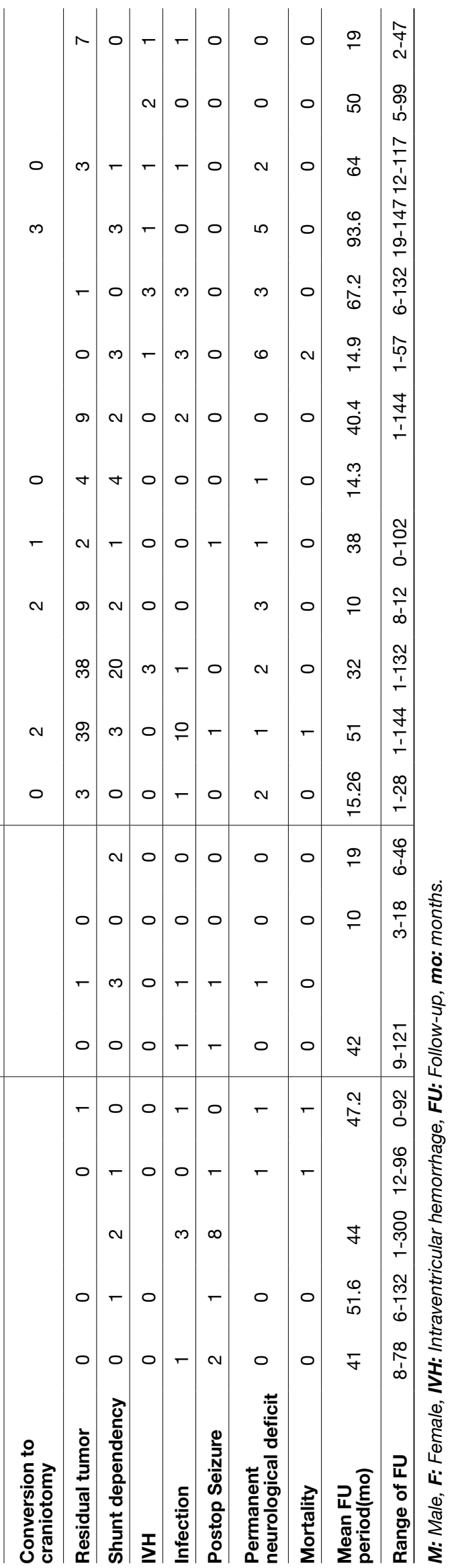




\section{DISCUSSION}

The anatomical location of CC makes its total excision difficult. The ideal surgical approach for the removal of CC is controversial (10). Taking advantage of dilated ventricles caused by obstruction of the foramen of Monro, transcortical transventricular microsurgical approach was considered to be the best strategy for a long time, as this dilation of the ventricles facilitates surgical access. However, this approach required frontal cortex incisions and lobar dissections of considerable length $(10,13)$. Postoperative CT examinations often showed extensive hypodensities related to parenchymal dissection and retraction. Such injuries, once considered an acceptable price in some cases, are now unacceptable (27).

The interhemispheric transcallosal approach was therefore designed and proposed in order to avoid this cortical infringement, as the corpus callosum is the only structure that needs to be sectioned to access the ventricle and the CC $(37,44,47)$. Different types of memory impairment, motor coordination and attention deficits have been reported in up to $83 \%$ of patients with CC who were operated via the transcallosal approach $(19,33)$. Another significant complication of this approach is venous infarction (43). The transcallosal interforniceal route also resulted in high rates of forniceal injury $(2,29)$.

Severe consequences of these approaches have led to the proposal of percutaneous techniques like stereotactic cyst aspiration without removal (10). Unfortunately recurrences were encountered in the short term $(26,32)$. The microsurgical approach via stereotactically guided minitubular retractors was developed to increase the precision of the approach, thereby minimizing the injury to the brain parenchyma $(4,6)$. No prominent side effects and morbidities are reported $(1,4,6,8)$.

Another development was achieved via the neuroendoscope as it enables a "simple" percutaneous procedure like aspiration but at the same time carries the potential of performing cyst resection. Difficulties encountered in the early years, such as blurring of the field or inability to grasp and remove the cysts, have been overcome by the accumulation of experience and the development of better instruments. Dual-instrument applications from a single working channel resulted in total excision rates of $82 \%(46)$.

Cortical incisions may lead to epilepsy and the conventional transfrontal approach is known to result in high rates of seizures. Incisions up to $3 \mathrm{~cm}$, and parenchymal dissections, which could be unduely extensive in the absence of guidance or navigation, resulted in seizure rates of up to $27 \%$ (13). Our literature review revealed an overall seizure rate of $13 \%$ for conventional surgery. The seizure rate in our 11 cases that underwent conventional surgery was $27 \%$ in which all the patients were seizure free after increasing doses of antiepileptic drugs. On the other hand, our seizure rates for minitubular or endoscopic resections were $0 \%$. Our literature review showed seizure rates of $4 \%$ for minitubular approach and $0.5 \%$ for endoscopic series. This is highly significant: smaller incisions, less invasive approaches lead to significantly lower rates of seizure. Thus the rationale of greater seizure rates for conventional approach compared to minitubular and endoscopic approaches can be attributed to longer cortical incision lengths. Furthermore, during the course of the conventional approach, retractor blades are used which may lead to cerebral infarction due to excessive force of retraction and accidental cutting of brain tissue (4). Furthermore, the retractor blade is generally used with a fixator that also increases the parenchymal damage due to continuous pulling force throughout the resection period. During the minitubular approach, there is no need for a fixator holding the lightweight cylindrical retractor since it stays suspended within the brain parenchyma immovably (4). The forces that create a parenchymal damage by retractor blade (conventional approach) versus cylindrical plastic retractor (minitubular approach) are different in magnitude. While the blade exerts disproportionate force in one direction, the cylindrical retractor distributes the forces equally over 360 degrees reducing the pressure considerably over unit area. The same argument is true for the endoscopic approach since the diameter of the endoscope $(2.7 \mathrm{~mm})$ is considerably smaller than the cylindrical retractor $(14 \mathrm{~mm})$ and no retractor blades are used.

The ideal treatment of CC must focus on total removal. A recent meta-analysis of $1278 \mathrm{CC}$ patients (583 microsurgical, 695 endoscopic) showed that the microsurgical group has a higher gross total resection rate, lower recurrence rate and lower reoperation rate compared to endoscopic group (39). In the present series, residual tumors were detected in three patients; two in the endoscopic and one in the conventional approach group. When residual tumor rates of the present series and our literature review are compared, the rates are $22 \%$ vs. $28 \%$ in the endoscopic, $0 \%$ vs. $3 \%$ in the minitubular and $0 \%$ vs. $2 \%$ in the conventional approach, respectively. As a result, the present series showed comparable results with the literature in that endoscopic approaches for the removal of CC have higher residual tumor rates compared to microsurgical approaches. In the present series, there were more favorable residual tumor ratios of $0 / 11(0 \%)$ in the conventional and $0 / 21(0 \%)$ in the minitubular approaches against $2 / 9(22 \%)$ in endoscopic approach $(p=0.024)$. The high rate of incomplete removal for endoscopic CC surgery is attributed to the anatomical location of the cyst, which is tucked up underneath the roof of the third ventricle and difficult to reach through a burrhole located near the coronal suture with a rigid endoscope. Studies on the use of novel approaches to overcome this anatomical difficulty, or with dual endoscopic instruments report higher rates of total removal compared to standard endoscopic methods $(7,22,46)$.

In the literature, most of the patients had symptoms of hydrocephalus on admission (39). Our literature review showed that $80 \%$ of endoscopically operated, $84 \%$ of minitubular approach and $75 \%$ of conventionally operated patients were hydrocephalic. In the present series, ventricular enlargement was present in all of the 41 patients except one (97\%). However with liberal use of cranial radiological examinations, especially $\mathrm{MRI}$, more patients are being diagnosed with CC in the absence of hydrocephalus. Optimal management of patients with CC and normal ventricles is unclear (45). Wait et al. 
reported that normal size ventricles are not a contraindication to endoscopic removal of CC (45). On the other hand, many authors advocate a wait-and-see approach $(15,41)$. In most patients, removal of the cyst leads to reduction in the ventricle size and resolution of hydrocephalus symptoms. In the present series, postoperative shunt dependency was independent of the type of surgical approach and this result was compatible with the literature (39).

Hemiparesis is a known but rare complication of CC surgery $(38,39,43)$. Sampath et al. reported postoperative hemiparesis in a patient whose craniotomy was unintentionally localized near the motor cortex. They also stated that the endoscopic approach with a far frontal trajectory is very unlikely to be associated with this type of morbidity (38). This statement was true for the current series since none of the patients that were operated via endoscopic approach had hemiparesis postoperatively. Also, none of the patients who were operated via stereotactically guided minitubular approach had hemiparesis postoperatively. Two of our patients had permanent hemiparesis, both of whom had undergone a conventional approach that was statistically significant $(p<0.05)$. On the other hand, in their meta-analysis Sheikh et al. reported that hemiparesis was independent of the surgery type. They stated that the overall rate of hemiparesis was $0.9 \%$ in endoscopic vs. $1.9 \%$ in the transcortical microscopic series which was statistically insignificant (39).

The only mortality in this series was seen in the conventional approach group. Patient 11, who had been diagnosed with CC eight years ago and refused surgery, presented comatose and could not be saved despite urgent intervention. This mortality shows the potential fatality of $\mathrm{CC}$ and corroborates to the literature regarding the lethality of CC $(34,40)$. Asymptomatic patients that were diagnosed with CC incidentally must be warned carefully against the possible forthcoming increased intracranial pressure (ICP) symptoms and fatality. In this series, more patients had presented with coma in the earlier years (Patient 12, 13, 14), whereas in the later periods the cardinal symptom had become headache. This situation is attributable to the ease of access to radiological imaging techniques in the later years.

Patients in the minitubular approach group had the best results in terms of completeness of removal, seizure rates and neurological deficit rates in both the present series and the literature review. This approach, unlike the other two, was stereotactically guided.

A major shortcoming of this report is its inability to include into its comparison the use of neuronavigation, which undoubtedly had a positive effect on the results. Studies performed on series using neuronavigation-assisted endoscopy and transfrontal microsurgery will be able to clarify this issue.

\section{CONCLUSION}

With respect to complication rates, stereotactic and endoscopic approaches are both safe and reliable compared to conventional microsurgical approach that has high rates of seizures and neurological deficit. Concerning completeness of removal, both microsurgical approaches are by far superior to neuroendoscopy. Stereotactic microsurgical approaches compare favorably in both respects with endoscopic and conventional microsurgical approaches.

\section{REFERENCES}

1. Abernathey CD, Davis DH, Kelly PJ: Treatment of colloid cysts of the third ventricle by stereotaxic microsurgical laser craniotomy. J Neurosurg 70(4):525-529, 1989

2. Aggleton JP, Brown MW: Episodic memory, amnesia, and the hippocampal-anterior thalamic axis. Behav Brain Sci 22(3):425-444, 1999

3. Alnaghmoosh N, Alkhani A: Colloid cysts in children, a clinical and radiological study. Childs Nerv Syst 22(5):514-516, 2006

4. Barlas $\mathrm{O}$, Karadereler S: Stereotactically guided microsurgical removal of colloid cysts. Acta Neurochir (Wien) 146(11):11991204, 2004

5. Boogaarts HD, Decq P, Grotenhuis JA, Le Guérinel C, Nseir $R$, Jarraya $B$, Djindjian $M$, Beems T: Long-term results of the neuroendoscopic management of colloid cysts of the third ventricle: A series of 90 cases. Neurosurgery 68(1):179-187, 2011

6. Cabbell KL, Ross DA: Stereotactic microsurgical craniotomy for the treatment of third ventricular colloid cysts. Neurosurgery 38(2):301-307, 1996

7. Chibbaro S, Champeaux C, Poczos P, Cardarelli M, Di Rocco F, laccarino C, Servadei F, Tigan L, Chaussemy D, George B, Froelich S, Kehrli P, Romano A: Anterior trans-frontal endoscopic management of colloid cyst: An effective, safe, and elegant way of treatment. Case series and technical note from a multicenter prospective study. Neurosurg Rev 37(2):235-241, 2014

8. Cohen-Gadol AA: Minitubular transcortical microsurgical approach for gross total resection of third ventricular colloid cysts: Technique and assessment. World Neurosurg 79(1):207. e7-10, 2013

9. de Witt Hamer PC, Verstegen MJ, De Haan RJ, Vandertop WP, Thomeer RT, Mooij JJ, van Furth WR: High risk of acute deterioration in patients harboring symptomatic colloid cysts of the third ventricle. J Neurosurg 96(6):1041-1045, 2002

10. Decq P: Endoscopy or microsurgery: Is the never-ending debate concerning the choice of surgical strategy for colloid cysts of the third ventricle still a topical issue or has it been resolved? World Neurosurg 80(5):498-499, 2013

11. Decq $P$, Le Guerinel $C$, Brugières $P$, Djindjian $M$, Silva $D$, Kéravel Y, Melon E, Nguyen JP: Endoscopic management of colloid cysts. Neurosurgery 42(6):1288-1294, 1998

12. Delitala A, Brunori A, Russo N: Supraorbital endoscopic approach to colloid cysts. Neurosurgery 69(2 Suppl Operative):ons176-182, 2011

13. Desai KI, Nadkarni TD, Muzumdar DP, Goel AH: Surgical management of colloid cyst of the third ventricle-a study of 105 cases. Surg Neurol 57(5):295-302, 2002

14. Grondin RT, Hader W, MacRae ME, Hamilton MG: Endoscopic versus microsurgical resection of third ventricle colloid cysts. Can J Neurol Sci 34(2):197-207, 2007

15. Grunert P, Hopf N, Perneczky A: Frame-based and frameless endoscopic procedures in the third ventricle. Stereotact Funct Neurosurg 68: 80-89, 1997 
16. Hellwig D, Bauer BL, Schulte M, Gatscher S, Riegel T, Bertalanffy $\mathrm{H}$ : Neuroendoscopic treatment for colloid cysts of the third ventricle: The experience of a decade. Neurosurgery 52:525-533, 2003

17. Hoffman CE, Savage NJ, Souweidane MM: The significance of cyst remnants after endoscopic colloid cyst resection: A retrospective clinical case series. Neurosurgery 73(2):233237,2013

18. Horn EM, Feiz-Erfan I, Bristol RE, Lekovic GP, Goslar PW, Smith KA, Nakaji P, Spetzler RF: Treatment options for third ventricular colloid cysts: Comparison of open microsurgical versus endoscopic resection. Neurosurgery 60:613-618, 2007

19. Hütter BO, Spetzger U, Bertalanffy H, Gilsbach JM: Cognition and quality of life in patients after transcallosal microsurgery for midline tumors. J Neurosurg Sci 41(1):123-129, 1997

20. Hwang DH, Townsend JC, Ilsen PF, Bright DC: Colloid cyst of the third ventricle. J Am Optom Assoc 67(4): 227-234, 1996

21. lacoangeli M, di Somma LG, Di Rienzo A, Alvaro L, Nasi $D$, Scerrati $M$ : Combined endoscopic transforaminaltranschoroidal approach for the treatment of third ventricle colloid cysts. J Neurosurg 120(6):1471-1476, 2014

22. Ibáñez-Botella G, Domínguez $M$, Ros $B$, De Miguel L, Márquez $B$, Arráez MA: Endoscopic transchoroidal and transforaminal approaches for resection of third ventricular colloid cysts. Neurosurg Rev 37(2):227-234, 2014

23. Jeffree RL, Besser $M$ : Colloid cyst of the third ventricle: $A$ clinical review of 39 cases. J Clin Neurosci 8:328-331, 2001

24. Kehler U, Brunori A, Gliemroth J, Nowak G, Delitala A, Chiappetta F, Arnold H: Twenty colloid cysts-comparison of endoscopic and microsurgical management. Minim Invasive Neurosurg 44:121-127, 2001

25. Kelly PJ, Goerss SJ, Kall BA: The stereotaxic retractor in computer-assisted stereotaxic microsurgery. Technical note. J Neurosurg 69(2):301-306, 1988

26. Kondziolka D, Lunsford LD: Stereotactic management of colloid cysts: Factors predicting success. J Neurosurg 75(1):45-51, 1991

27. Lanzino G: Retractorless brain surgery. J Neurosurg 116(2):290, 2012

28. Levine NB, Miller MN, Crone KR: Endoscopic resection of colloid cysts: Indications, technique, and results during a 13year period. Minim Invasive Neurosurg 50(6):313-317, 2007

29. Lewis Al, Crone KR, Taha J, van Loveren HR, Yeh HS, Tew JM Jr: Surgical resection of third ventricle colloid cysts. Preliminary results comparing transcallosal microsurgery with endoscopy. J Neurosurg 81:174-178, 1994

30. Longatti P, Godano U, Gangemi M, Delitala A, Morace E, Genitori L, Alafaci C, Benvenuti L, Brunori A, Cereda C, Cipri S, Fiorindi A, Giordano F, Mascari C, Oppido PA, Perin A, Tripodi M; Italian Neuroendoscopy Group: Cooperative study by the Italian neuroendoscopy group on the treatment of 61 colloid cysts. Childs Nerv Syst 22:1263-1267, 2006

31. Maeder PP, Holtas SI, Basibüyük LN, Salford LG, Tapper UA, Brun A: Colloid cysts of the third ventricle: Correlation of MR and CT findings with histology and chemical analysis. AJNR 11:575-581, 1990

32. Mathiesen T, Grane P, Lindquist C, von Holst H: High recurrence rate following aspiration of colloid cysts in the third ventricle. J Neurosurg 78(5):748-752, 1993
33. McMackin D, Cockburn J, Anslow P, Gaffan D: Correlation of fornix damage with memory impairment in six cases of colloid cyst removal. Acta Neurochir (Wien) 135(1-2):12-18, 1995

34. Opeskin K, Anderson RM, Lee KA: Colloid cyst of the 3rd ventricle as a cause of acute neurological deterioration and sudden death. J Paediatr Child Health 29(6):476-477, 1993

35. Parwani AV, Fatani IY, Burger PC, Erozan YS, Ali SZ: Colloid cyst of the third ventricle: Cytomorphologic features on stereotactic fine-needle aspiration. Diagn Cytopathol 27(1):2731, 2002

36. Patel N, Rao VA, Heilman-Espinoza ER, Lai R, Quesada RA, Flint AC: Simple and reliable determination of the modified Rankin Scale in neurosurgical and neurological patients: The mRS-9Q. Neurosurgery 71(5): 971-975, 2012

37. Petrucci RJ, Buchheit WA, Woodruff GC, Karian JM, DeFilipp GJ: Transcallosal parafornicial approach for third ventricle tumors: Neuropsychological consequences. Neurosurgery 20(3):457-464, 1987

38. Sampath R, Vannemreddy P, Nanda A: Microsurgical excision of colloid cyst with favorable cognitive outcomes and short operative time and hospital stay: Operative techniques and analyses of outcomes with review of previous studies. Neurosurgery 66(2):368-374, 2010

39. Sheikh AB, Mendelson ZS, Liu JK: Endoscopic versus microsurgical resection of colloid cysts: A systematic review and meta-analysis of 1,278 patients. World Neurosurg 82(6):1187-1197, 2014

40. Shemie S, Jay V, Rutka J, Armstrong D: Acute obstructive hydrocephalus and sudden death in children. Ann Emerg Med 29(4):524-528, 1997

41. Solaroglu I, Beskonakli E, Kaptanoglu E, Okutan O, Ak F, Taskin Y: Transcortical-transventricular approach in colloid cysts of the third ventricle: Surgical experience with 26 cases. Neurosurg Rev 27(2):89-92, 2004

42. Sribnick EA, Dadashev VY, Miller BA, Hawkins S, Hadjipanayis CG: Neuroendoscopic colloid cyst resection: A case cohort with follow-up and patient satisfaction. World Neurosurg 81(34):584-593, 2014

43. Symss NP, Ramamurthi R, Kapu R, Rao SM, Vasudevan MC, Pande A, Cugati G: Complication avoidance in transcallosal transforaminal approach to colloid cysts of the anterior third ventricle: An analysis of 80 cases. Asian J Neurosurg 9(2):5157,2014

44. Timurkaynak E, Izci Y, Acar F: Transcavum septum pellucidum interforniceal approach for the colloid cyst of the third ventricle. Operative nuance. Surg Neurol 66(5):544-547, 2006

45. Wait SD, Gazzeri R, Wilson DA, Abla AA, Nakaji P, Teo C: Endoscopic colloid cyst resection in the absence of ventriculomegaly. Neurosurgery 73(1 Suppl Operative):39-47, 2013

46. Wilson DA, Fusco DJ, Wait SD, Nakaji P: Endoscopic resection of colloid cysts: Use of a dual-instrument technique and an anterolateral approach. World Neurosurg 80(5):576-583, 2013

47. Winkler PA, Weis S, Wenger E, Herzog C, Dahl A, Reulen HJ: Transcallosal approach to the third ventricle: Normative morphometric data based on magnetic resonance imaging scans, with special reference to the fornix and forniceal insertion. Neurosurgery 45(2):309-319, 1999

48. Zohdi A, El Kheshin S: Endoscopic approach to colloid cysts. Minim Invasive Neurosurg 49(5):263-268, 2006 